\title{
The stereostructure of candicidin D
}

\author{
Katarzyna Szwarc, Paweł Szczeblewski, Paweł Sowiński, Edward Borowski and Jan Pawlak
}

The candicidin D stereostructure was established based on NMR studies including DQF-COSY, ROESY, HSQC and HMBC experiments. The relative configurations of the candicidin D stereogenic centers were assigned as the following: $9 R^{*}, 11 S^{*}$, $13 S^{*}, 15 R^{*}, 17 S^{*}, 18 R^{*}, 19 S^{*}, 21 R^{*}, 36 S^{*}, 37 R^{*}, 38 S^{*}, 40 S^{*}$ and $41 S^{*}$. The geometry of the heptaene chromophore was defined as $22 E, 24 E, 26 Z, 28 Z, 30 E, 32 E$ and $34 E$.

The Journal of Antibiotics (2015) 68, 504-510; doi:10.1038/ja.2015.17; published online 25 February 2015

\section{INTRODUCTION}

The antifungal antibiotic candicidin $\mathrm{D}$, an aromatic heptaene ${ }^{1}$ macrolide, is the main component of the candicidin complex produced by Streptomyces griseus IMRU 3570. 2,3 This antibiotic complex belongs to the polyene macrolide family, the most promising antifungal agents for topical and systemic fungal infection treatment due to their unique (among antifungal chemotherapeutics) properties. These properties include a high antifungal activity, broad antifungal spectrum, fungicidal action and the ability to overcome fungal multidrug resistance by not being the substrates of multidrugresistant proteins exporting the drugs from the fungal cells. ${ }^{4}$

Candicidins, as well as other polyene macrolide aromatic subgroup, are of interest due to their highest antifungal activity among polyene macrolides ${ }^{3}$ and other activities comprising inhibitory action on prostate cancer growth ${ }^{5}$ as well as their significant antiviral activity. ${ }^{6}$ However, these compounds exhibit several negative features, such as the lack of water solubility and rather high animal toxicity, which limit the applications for their clinical use in the treatment of systemic fungal infections. Nevertheless, topical applications of the candicidin complex, partricins, levorins and trichomycin complexes are still continued.

Efforts have been made to overcome the compounds' disadvantages by chemical modifications. ${ }^{7}$ In the latter case, the achievements have not been satisfactory due to the lack of structural data indispensable for the rational modification of native compounds. The available structural data comprise levorins, ${ }^{8,9}$ trichomycins, ${ }^{10,11}$ 67-121-A, 67$121-\mathrm{C},{ }^{12}$ perimicin $\mathrm{A}^{13}$ and aureofacin complex components, vacidin ${ }^{14}$ (syn. partricin $\mathrm{A}^{15}$ ) and gedamycin ${ }^{16}$ (syn. partricin $\mathrm{B}^{15}$ ). However, the first discovered and most studied antifungal aromatic heptaenes, candicidins, ${ }^{2}$ lack complete stereostructures. ${ }^{17}$ In this study, we report the NMR studies of candicidin D, which result in its complete stereostructure assignment (Figure 1).

\section{RESULTS AND DISCUSSION}

The candicidin complex was derivatized by $\mathrm{N}$-acetylation followed by esterification with diazomethane, which facilitated the purification process and chromatographic separation of the candicidin complex components. This type of derivative allowed for utilization of a wide

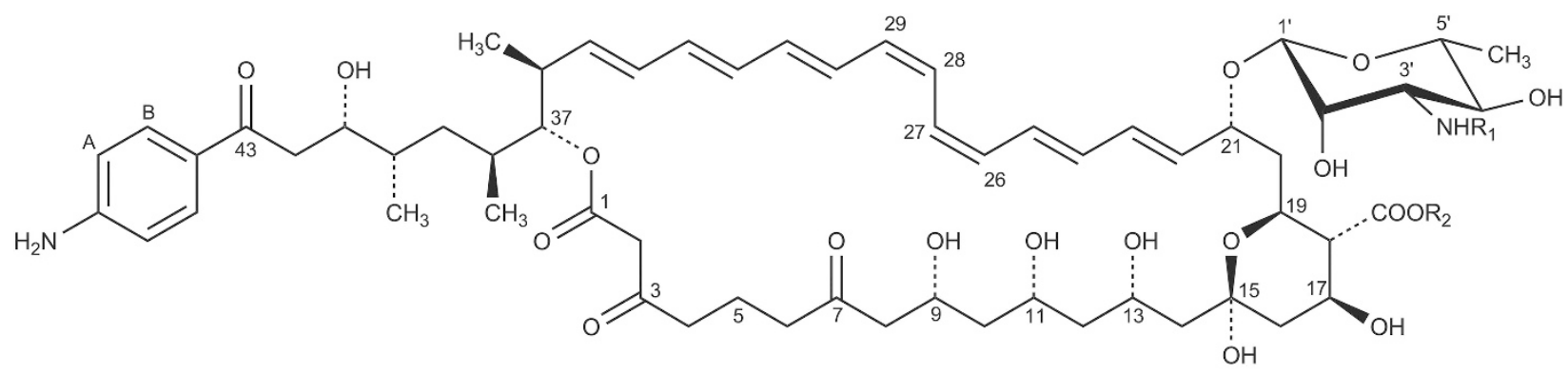

Candicidin D (1)

3'-N-acetylcandicidin D methyl ester (2)
$\mathrm{R}_{1}=\mathrm{H} ; \mathrm{R}_{2}=\mathrm{H}$

$\mathrm{R}_{1}=\mathrm{COCH}_{3} ; \mathrm{R}_{2}=\mathrm{CH}_{3}$

Figure 1 The structures of candicidin D (1) and its derivative, $3^{\prime}-\mathrm{N}$-acetylcandicidin D methyl ester (2). 
variety of NMR solvents. The isolated $3^{\prime}-\mathrm{N}$-acetylcandicidin D methyl ester (2) (Figure 1) was analyzed by UV, MS, IR and NMR methods.

The UV spectrum (Figure 2) of the methyl ester of $3^{\prime}-N$-acetylcandicidin D (2) displayed three absorption maxima at $\lambda_{1}=360 \mathrm{~nm}, \lambda_{2}=380 \mathrm{~nm}$ and $\lambda_{3}=401 \mathrm{~nm}$, which were attributed to seven conjugated double bonds. The intensity of the longest wavelength absorption peak at $401 \mathrm{~nm}$ was lower than that at $380 \mathrm{~nm}$. According to the literature, ${ }^{3}$ this result suggested the presence of internal cis double bonds, which was further proved by our NMR studies.

The ESI quadrupole time-of-flight mass spectrum (ESI-Q-TOF MS) of the methyl ester of $3^{\prime}-N$-acetylcandicidin $\mathrm{D}(2)$ showed the ion at $\mathrm{m} / z 1163.5973$ of the (M-H) ${ }^{-}$type (calculated for $\mathrm{C}_{62} \mathrm{H}_{88} \mathrm{O}_{19} \mathrm{~N}_{2} \mathrm{~m} / \mathrm{z}$ 1163.5908 of $(\mathrm{M}-\mathrm{H})^{-}$type, error of mass measurement accuracy $\Delta=5.6$ p.p.m.). Taking into account performed derivatization of the antibiotic molecule, the MW of unsubstituted candicidin D (1) was

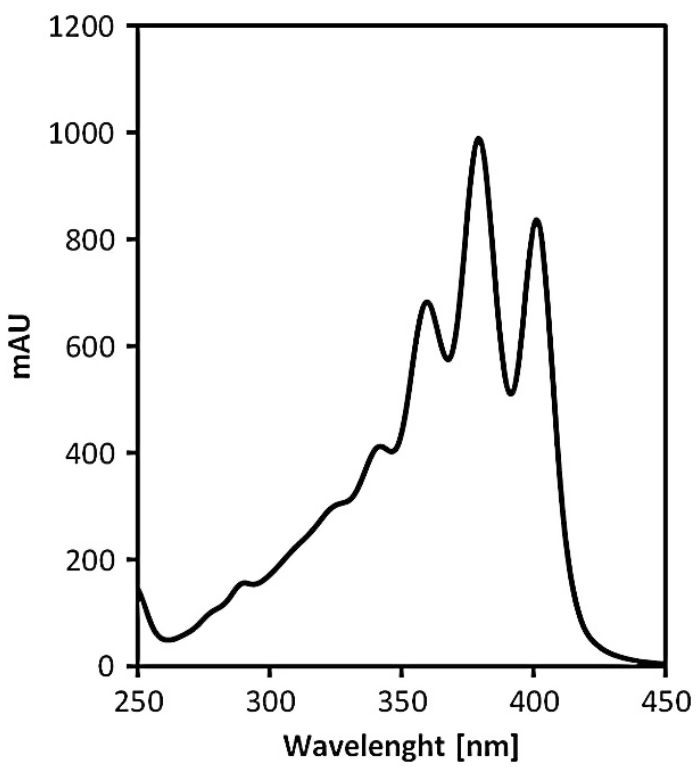

Figure 2 The UV spectrum of $3^{\prime}-N$-acetylcandicidin D methyl ester (2) in methanol. deduced as 1108 mass units, which corresponded to its known molecular formula, $\mathrm{C}_{59} \mathrm{H}_{84} \mathrm{O}_{18} \mathrm{~N}_{2} \cdot{ }^{17}$

The IR spectrum of $\mathbf{2}$ was recorded to fulfill the new compounds (Figure 3). However, due to the multifunctional character of the candicidin D molecule, an IR spectrum may be useful as a fingerprinting standard.

The NMR studies of 2, consisting of double-quantum filteredCOSY (DQF-COSY), ROESY, HSQC and HMBC experiments, allowed for full proton and carbon assignments, which are presented in Table 1 and Table 2, respectively. The vicinal coupling constants, shown in Table 1 were extracted from $1 \mathrm{D}^{1} \mathrm{H}$ NMR spectrum of 2 , and in some cases from the analysis of the phase structure of the cross-peaks observed in the DQF-COSY spectrum of $\mathbf{2}$.

The DQF-COSY spectrum analysis of 2 revealed the connectivities within five of the six structural blocks, namely C4-C6, C8-C14, C16$\mathrm{C} 42$, which are aromatic and sugar moieties that are separated by the quaternary carbons C-1, C-3, C-7, C-15 and C-43 as well as by a glycosidic bond. The isolated methylene group, C-2, was found by long-range heteronuclear connectivities observed in the $\mathrm{HMBC}$ spectrum (2a-H/C-1, 2b-H/C-1, 2a-H/C-3 and 2b-H/C-3).

The sequence and orientation of the aforementioned structural blocks were assembled based on the HMBC experiment, the results of which were in accordance with data derived from the ROESY spectrum. Thus, blocks $\mathrm{C} 4-\mathrm{C} 6$ and $\mathrm{C} 8-\mathrm{C} 14$ were linked via $\mathrm{C}-7$ due to couplings $8 \mathrm{~b}-\mathrm{H} / \mathrm{C}-7$ and $6-\mathrm{H} / \mathrm{C}-7$. The connection of the blocks C8-C14 and C16-C42 resulted from 14a-H/C-15 and 16a-H/C-15. The acyloxy proton chemical shift $(37-\mathrm{H}, 5.04$ p.p.m.), associated with correlations $2 \mathrm{a}-\mathrm{H} / \mathrm{C}-1,2 \mathrm{~b}-\mathrm{H} / \mathrm{C}-1$ and $37-\mathrm{H} / \mathrm{C}-1$, revealed the presence of the lactone bond between $\mathrm{C}-1$ and $\mathrm{C}-37$. The macrolactone ring was finally closed by the $\mathrm{C}-3$ keto group due to the couplings $2 \mathrm{a}-\mathrm{H} / \mathrm{C}-3,2 \mathrm{~b}-\mathrm{H} / \mathrm{C}-3$, 4a-H/C-3 and 4b-H/C-3. The attachment of aromatic moiety via $\mathrm{C}-43$ to the $\mathrm{C} 16-\mathrm{C} 42$ fragment was established based on $42 \mathrm{a}-\mathrm{H} / \mathrm{C}-43,42 \mathrm{~b}-\mathrm{H} / \mathrm{C}-43$ and B-H/C-43 connectivities. The location of the $3^{\prime}-N$-acetylmycosaminyl substituent at $\mathrm{C}-21$ was noted by the $1^{\prime}-\mathrm{H} / \mathrm{C}-21$ correlation.

The geometry of the heptaene chromophore was established as $22 E$, $24 E, 26 Z, 28 Z, 30 E, 32 E$ and $34 E$, as derived from a set of vicinal coupling constants that were extracted from high-resolution DQFCOSY spectrum. The following coupling constants, $J_{22,23}, J_{24,25}, J_{30,31}$, $J_{32,33}, J_{34,35}$, contained within a range from 15 to $16 \mathrm{~Hz}$, determined $\mathrm{E}$

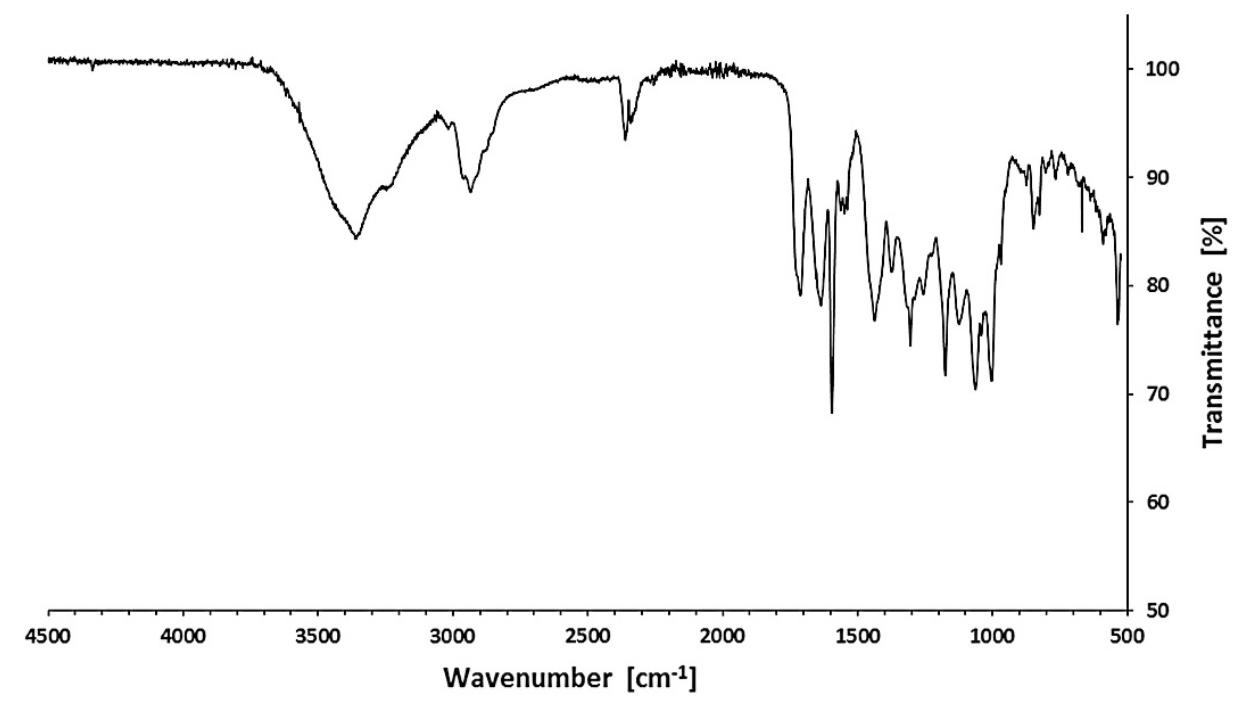

Figure 3 The IR spectrum of 3'-N-acetylcandicidin D methyl ester (2). The following bands were recorded: $3350,2910,1710$ and $1630 \mathrm{~cm}^{-1}$. 
Table $1{ }^{1} \mathrm{H}$ NMR data for 2

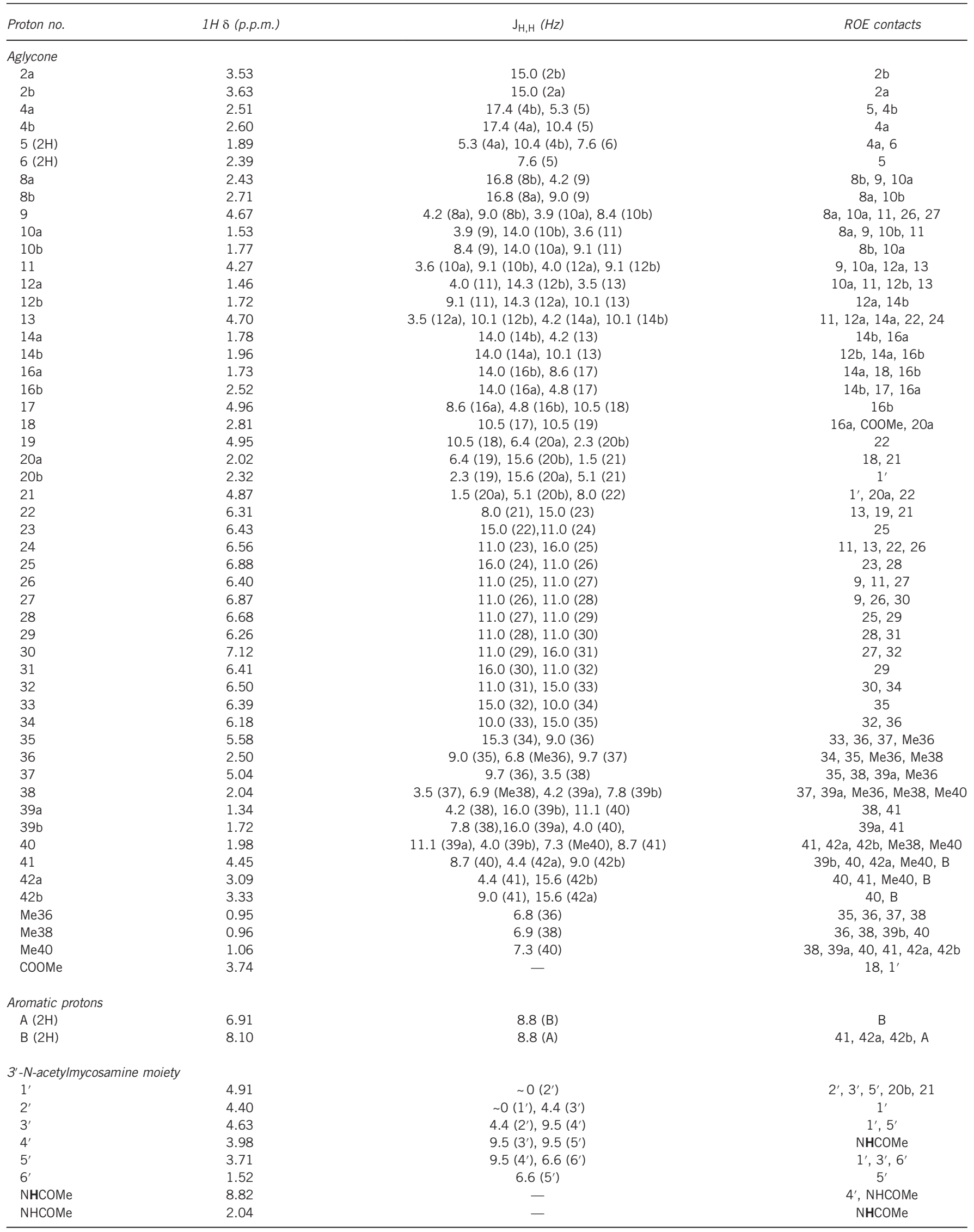


Table $2{ }^{13} \mathrm{C}$ NMR data for 2

\begin{tabular}{|c|c|c|c|}
\hline $13 \mathrm{C}$ atom no. & $13 C \delta$ (p.p.m.) & $13 \mathrm{C}$ atom no. & $13 C \delta$ (p.p.m.) \\
\hline Aglycone & & 32 & 132.6 \\
\hline 1 & 166.7 & 33 & 133.5 \\
\hline 2 & 48.5 & 34 & 131.5 \\
\hline 3 & 201.6 & 35 & 137.3 \\
\hline 4 & 42.0 & 36 & 40.0 \\
\hline 5 & 17.1 & 37 & 81.1 \\
\hline 6 & 42.4 & 38 & 31.0 \\
\hline 7 & 208.8 & 39 & 36.8 \\
\hline 8 & 50.1 & 40 & 36.3 \\
\hline 9 & 67.2 & 41 & 71.9 \\
\hline 10 & 43.7 & 42 & 41.8 \\
\hline 11 & 72.2 & 43 & 197.5 \\
\hline 12 & 43.8 & Me36 & 16.1 \\
\hline 13 & 68.8 & Me38 & 12.0 \\
\hline 14 & 46.5 & $\mathrm{Me} 40$ & 15.4 \\
\hline 15 & 97.9 & coOMe & 173.7 \\
\hline 16 & 44.8 & coOMe & 51.3 \\
\hline 17 & 66.0 & \multicolumn{2}{|c|}{ Aromatic carbons } \\
\hline 18 & 58.2 & $\mathrm{CA}$ & 113.0 \\
\hline 19 & 66.0 & $\mathrm{CB}$ & 131.0 \\
\hline 20 & 37.8 & $\mathbf{C}^{*} \mathrm{CO}$ & 154.1 \\
\hline 21 & 76.0 & $\mathrm{C} * \mathrm{NH} 2$ & 126.7 \\
\hline 22 & 136.8 & & \\
\hline 23 & 130.3 & \multicolumn{2}{|c|}{$3^{\prime}-N$-acetylmycosamine moiety } \\
\hline 24 & 134.2 & $1^{\prime}$ & 98.3 \\
\hline 25 & 127.2 & $2^{\prime}$ & 70.6 \\
\hline 26 & 133.1 & $3^{\prime}$ & 55.8 \\
\hline 27 & 124.8 & $4^{\prime}$ & 71.4 \\
\hline 28 & 124.8 & $5^{\prime}$ & 74.2 \\
\hline 29 & 130.5 & $6^{\prime}$ & 18.0 \\
\hline 30 & 128.7 & NHCOOMe & 170.7 \\
\hline 31 & 134.2 & NHCOOMe & 22.4 \\
\hline
\end{tabular}

geometry; $J_{26,27}$ and $J_{28,29}$, equal to $11 \mathrm{~Hz}$, are indicative of the presence of two double bonds with $Z$ geometry. This assignment was in full agreement with the ROEs of $25-\mathrm{H} / 28-\mathrm{H}, 26-\mathrm{H} / 27-\mathrm{H}, 27-\mathrm{H} /$ $30-\mathrm{H}$ and $28-\mathrm{H} / 29-\mathrm{H}$.

The chemical shifts of the heptaene chromophore resonances observed in the ${ }^{13} \mathrm{C}$ NMR spectrum of 2 (C-25, C-27, C-28 and C-30) were shielded by $\sim 5$ p.p.m. due to the C25-C28 and C27-C30 $\gamma$ effects. ${ }^{18}$ Consequently, all olefinic carbons signals appear in wider range (124.5-137.0 p.p.m.) compared with the more condensed correlation patterns in all trans-heptaenes (130-138 p.p.m.). ${ }^{19,20}$ The proton chemical shifts $(25-\mathrm{H}, 27-\mathrm{H}, 28-\mathrm{H}$ and $30-\mathrm{H})$ reflected deshielding effects typical of cis double bonds, ${ }^{21}$ which explains why the signals of all olefinic protons occupied a range of chemical shifts almost twice as wide as that of non-aromatic heptaenes.

The C15-C21 segment geometry was derived as follows: the characteristic C-15 chemical shift observed in the ${ }^{13} \mathrm{C}$ NMR spectrum at 97.9 p.p.m. revealed the presence of a hemiketal carbon. This chemical shift suggested the existence of a six-membered hemiketal ring with an oxygen bridge between C-15 and C-19, which had only been previously suggested. ${ }^{17}$ Taking into account the values of vicinal coupling constants $\left(J_{16 \mathrm{a}, 17}=8.6 \mathrm{~Hz}, J_{17,18}=10.5 \mathrm{~Hz}, J_{18,19}=10.5 \mathrm{~Hz}\right)$, the orientation of all protons in hemiketal ring was established as an axial, and thereby the hemiketal ring was found to adopt a chair conformation. The antiperiplanar orientation of proton $20 \mathrm{a}-\mathrm{H}$ with relation to the $19-\mathrm{H}$ resulted from the vicinal coupling constant
$J_{19,20 \mathrm{a}}=6.0 \mathrm{~Hz}$ and $\mathrm{ROE} 18-\mathrm{H} / 20 \mathrm{a}-\mathrm{H}$. The remaining hemiketal ring substituent, the C-14 methylene group, was determined to occupy an equatorial position on ROEs: $14 \mathrm{a}-\mathrm{H} / 16 \mathrm{a}-\mathrm{H}$ and $14 \mathrm{~b}-\mathrm{H} / 16 \mathrm{~b}-\mathrm{H}$. The DQF-COSY data, $J_{20 \mathrm{a}, 21}=1.5 \mathrm{~Hz}, J_{20 \mathrm{~b}, 21}=5.1 \mathrm{~Hz}, J_{21,22}=8.0 \mathrm{~Hz}$, combined with the ROEs, $19-\mathrm{H} / 22-\mathrm{H}$ and $21-\mathrm{H} / 23-\mathrm{H}$, situated the C15-C21 fragment in relation to the heptaene chromophore plane. On the basis of this study, the relative configuration of chiral centers within the discussed fragment was assigned as $15 R^{\star}, 17 S^{\star}, 18 R^{\star}, 19 S^{\star}$ and $21 R^{\star}$.

The C8-C14 fragment geometry of 2 was established based on the scalar couplings and adequate ROEs. The hydroxymethine protons, coupled to four protons of adjacent methylene groups, exhibited characteristic multiplicity resulting from two pairs of small (from 3.5 to $4.2 \mathrm{~Hz}$ ) and large (from 8.4 to $10.0 \mathrm{~Hz}$ ) vicinal couplings. This regular alignment of the protons, $9-\mathrm{H}, 11-\mathrm{H}, 13-\mathrm{H}$, is supported by a set of ROEs, as follows: 9-H/26-H, 9-H/27-H, 11-H/24-H, 11-H/26-H, 13-H/22-H, 13-H/24-H (Figure 4). Thus, the C8-C14 segment relative configuration was defined as $9 R^{\star}, 11 S^{\star}$ and $13 S^{\star}$.

Within the C4-C6 fragment, we observed a strong, coupled six-spin system in the DQF-COSY spectrum. However, we established the mutual orientation of the fragments $\mathrm{C} 4-\mathrm{C} 6$ and $\mathrm{C} 8-\mathrm{C} 14$ by $8 \mathrm{a}-\mathrm{H} / 6-\mathrm{H}$ ROE. This Overhauser effect correlated with the ROEs $(8 \mathrm{a}-\mathrm{H} / 10 \mathrm{a}-\mathrm{H}$, 10a-H/12a-H, 14a-H/16a-H and 9-H/11-H, 11-H/13-H) strongly suggested a full, stretched conformation of the C6-C14 fragment. The conformation was determined by the aforementioned spatial relationships of the hydroxymethine protons to the heptaene chromophore (Figure 4).

The conformation determination of the mycosaminyl substituent resulted from the analysis of the vicinal coupling constants: $J_{2^{\prime}, 3^{\prime}}=4.4$ $\mathrm{Hz}, J_{3^{\prime}, 4^{\prime}}=9.5 \mathrm{~Hz}, J_{4^{\prime}, 5^{\prime}}=9.5 \mathrm{~Hz}$. This data pointed out the chair conformation with $3^{\prime}-\mathrm{H}, 4^{\prime}-\mathrm{H}$ and $5^{\prime}-\mathrm{H}$ in axial positions, while $2^{\prime}-\mathrm{H}$ was found to be equatorial. The $\beta$-configuration of the glycosidic bond was assigned from ROEs: $1^{\prime}-\mathrm{H} / 3^{\prime}-\mathrm{H}, 1^{\prime}-\mathrm{H} / 5^{\prime}-\mathrm{H}$ and $3^{\prime}-\mathrm{H} / 5^{\prime}-\mathrm{H}$. The $\mathrm{D}$-configuration of the mycosamine moiety was determined by the comparison of the specific rotations of $[\alpha]-\mathrm{D}-\mathrm{O}$-methyl- $\mathrm{N}$-acetylmycosaminide $\left([\alpha]_{\mathrm{D}}^{20}+46.0 \quad(c=1\right.$, methanol), obtained via standard deglycosylation of the $\mathrm{N}$-acetylcandicidin complex with that obtained from nystatin $A_{1}\left([\alpha]_{\mathrm{D}}^{23}+47.0 \quad(c=0.9\right.$, ethanol $){ }^{22}$ These specific rotations were comparable. The complete stereostructure of mycosamine from nystatin was previously elucidated by specific chemical degradation $^{23}$ and its resynthesis. ${ }^{24}$

It was assumed during elucidation of the stereochemistry of the C36-C42 fragment that one major conformer population represented it. The vicinal coupling constants within the fragment exhibited both small and large values, which indicated that the rotation of the side chain is limited due to the steric interactions. On the basis of scalar couplings and ROEs (Figure 5, Table 1), the relative configuration of the C36-C42 fragment was established as $36 S^{\star}, 37 R^{\star}, 38 S^{\star}, 40 S^{\star}, 41 S^{\star}$. The absolute configuration was deduced as follows. Within the fragment C36-C42, only one of two enantiomers possible for closing the macrolactone ring was in full agreement with the spectral data, situating the polyol chain above the chromophore plane. In the case of the opposite configuration of the discussed fragment, the lactone bond should be located below the chromophore plane. This location would imply the crossing of the chromophore and polyol chains. As a consequence, the distance between the chromophore and the C4-C6 fragment protons would be reduced, and thereby the appropriate correlations in the ROESY spectrum should be observed. Such a conformation of the macrolactone ring would disrupt the regular alignment of the C9-C11 fragment, and the evidence of this was described in this study. 


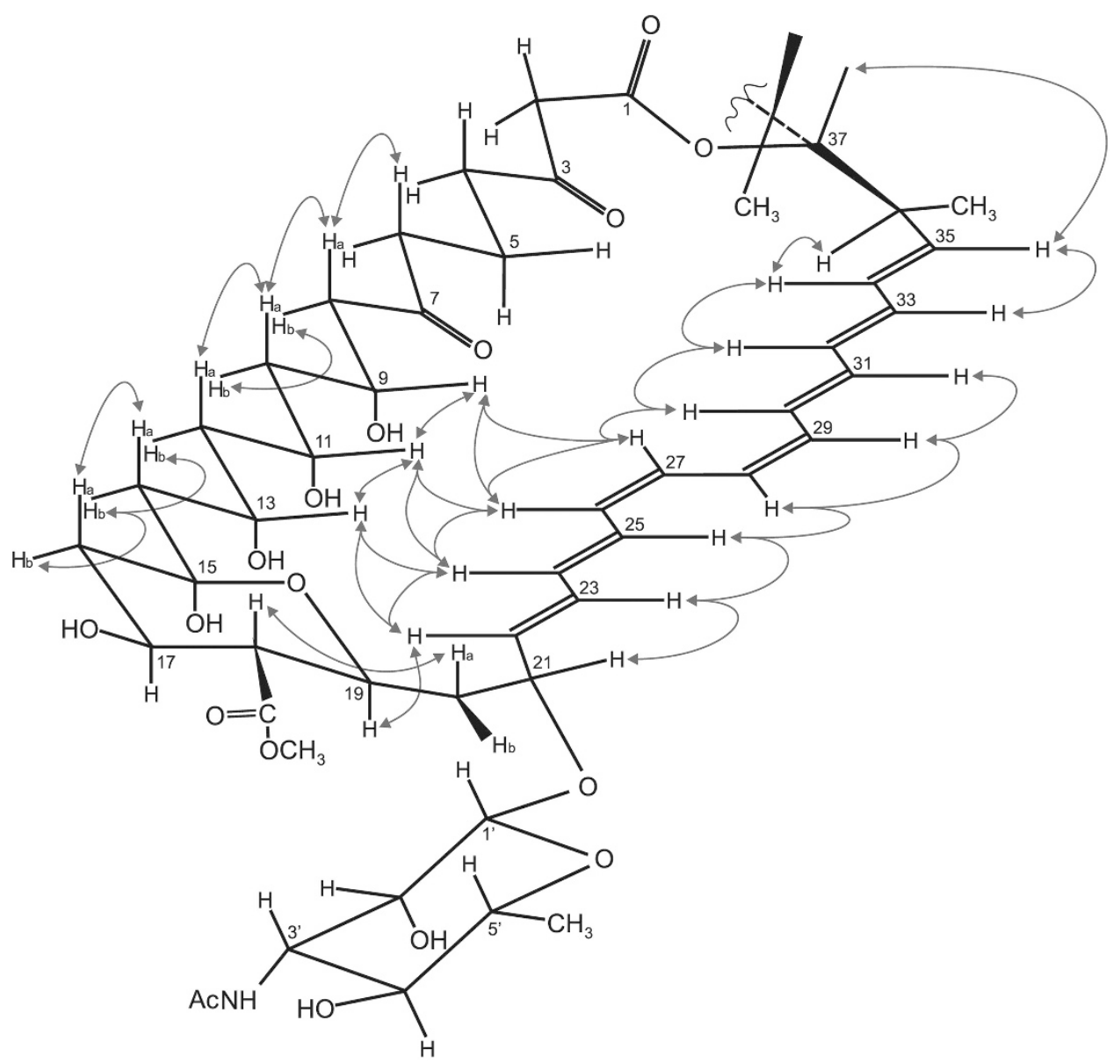

$\neg$ Selected ROEs, essential to establish conformation of macrolactone ring.

Figure 4 The stereostructure of $3^{\prime}-N$-acetylcandicidin D methyl ester (2). Diagnostic ROEs, observed in the ROESY spectrum of 2, are depicted as bidirectional arrows.

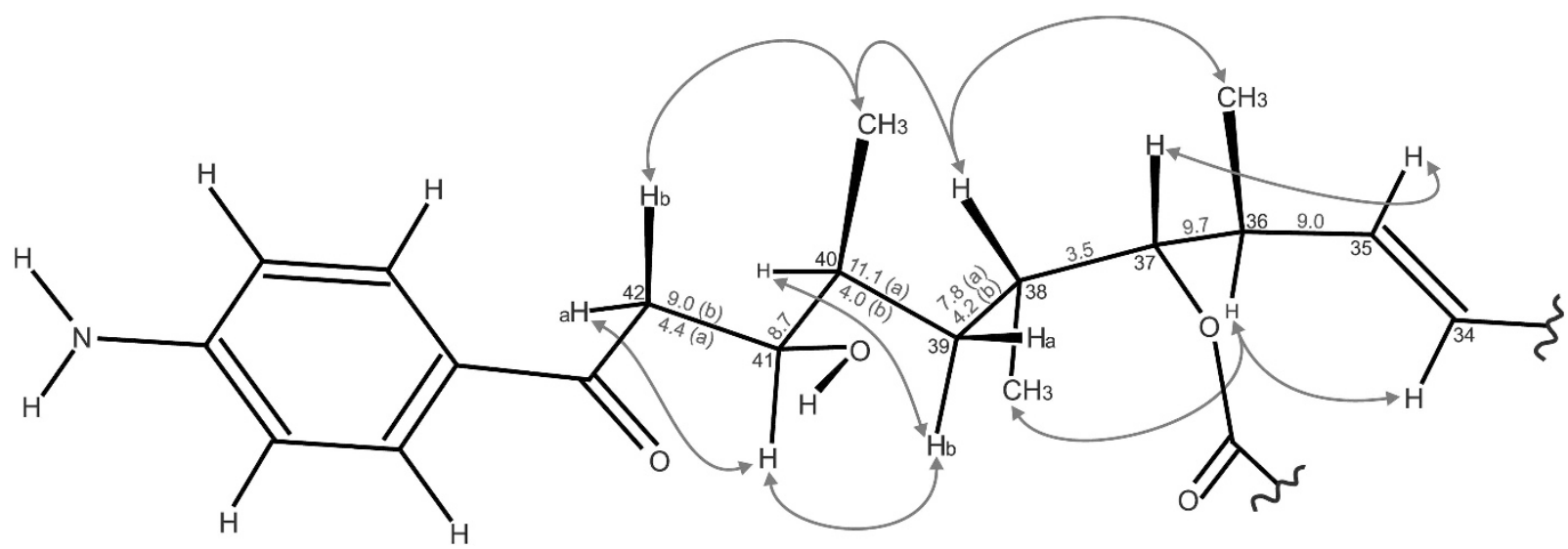

Figure 5 The candicidin D side chain configuration and conformation. Diagnostic ROEs, observed in the ROESY spectrum of 2, are depicted as bidirectional arrows. The values of appropriate coupling constants are situated near the bonds.

\section{METHODS}

Candicidin complex

A crude candicidin complex sample, with an extinction coefficient UV $\lambda_{\max }(\mathrm{MeOH}) 196(380) \mathrm{nm}$ ( 20\% purity), was supplied by Tarchomin Pharmaceutical Industry, 'Polfa' (Warsaw, Poland).
$3^{\prime}$-N-acetylcandicidin D methyl ester (2)

The crude candicidin complex was $\mathrm{N}$-acetylated by the following procedure: to suspension of $200 \mathrm{mg}$ of candicidin complex in $\mathrm{MeOH} / \mathrm{H}_{2} \mathrm{O}(9: 1,20 \mathrm{ml})$, acetic anhydride $(80 \mu \mathrm{l})$ was added. The reaction was carried out at room temperature, and its progress was monitored by TLC (Merck, Darmstadt, Germany) 
using the solvent system $\mathrm{EtOAc} / \mathrm{AcOH} / \mathrm{H}_{2} \mathrm{O}(4: 1: 1)$. After 30 min, the reaction mixture was centrifuged, and $5 \mathrm{ml}$ of $n$-butanol was added to the supernatant. A volume of the resulting solution was reduced to $\sim 1 \mathrm{ml}$ under reduced pressure. The product was precipitated from an $n$-butanol solution with $30 \mathrm{ml}$ of dry ethyl ether and centrifuged. The precipitate was washed three times with $30 \mathrm{ml}$ of dry ethyl ether and dried under reduced pressure to yield the $\mathrm{N}$-acetylated candicidin complex $(70 \mathrm{mg})$. The procedure was repeated several times to obtain the required amount of final product.

$3^{\prime}-N$-acetylcandicidin complex $(5.3 \mathrm{mg})$ was purified by flash chromatography on Merck Kieselgel 60 high-purity grade silica gel, $0.063-0.200 \mathrm{~mm}$, using the solvent system $\mathrm{CHCl}_{3} / \mathrm{MeOH} / \mathrm{H}_{2} \mathrm{O}$ (5:2:0.2). The obtained $3^{\prime}-\mathrm{N}$ acetylcandicidin complex $(480 \mathrm{mg})$, UV $\lambda_{\max }(\mathrm{MeOH}) 644(380) \mathrm{nm}$, was dissolved in $\mathrm{MeOH} / \mathrm{H}_{2} \mathrm{O}$ (9:1, $\left.150 \mathrm{ml}\right)$, and diazomethane in ethyl ether was added dropwise. The reaction was performed at room temperature, and its progress was monitored by TLC (Merck, Darmstadt, Germany) using the solvent system EtOAc/AcOH/ $\mathrm{H}_{2} \mathrm{O}$ (4:1:1). After further addition of $35 \mathrm{ml}$ of $n$-butanol, methanol and water were evaporated under reduced pressure. The complex was then precipitated from $n$-butanol with $120 \mathrm{ml}$ of dry ethyl ether and centrifuged. The precipitate was washed three times with $50 \mathrm{ml}$ of dry ethyl ether and dried under reduced pressure to yield a crude mixture $(320 \mathrm{mg})$, UV $\lambda_{\max }(\mathrm{MeOH}) 960(380) \mathrm{nm}$. The flash chromatography on the Merck Kieselgel 60 high-purity grade silica gel, $0.063-0.200 \mathrm{~mm}$, using the solvent system $\mathrm{CHCl}_{3} / \mathrm{MeOH} / \mathrm{H}_{2} \mathrm{O}$ (5:0.75:0.075) was performed to separate the product from the non-esterified antibiotics and obtain the esterified mixture $(110 \mathrm{mg}), \mathrm{UV}$ $\lambda_{\max }(\mathrm{MeOH}) 966(380) \mathrm{nm}$.

The purification of $3^{\prime}-\mathrm{N}$-acetylcandicidin D methyl ester (2) from the derivatized antibiotic complex $(110 \mathrm{mg})$ was performed using HPLC on a Merck-Hitachi apparatus L-6200A (Hitachi, Tokyo, Japan), equipped with a Merck-Hitachi L-4250 UV-VIS detector (Hitachi) $(380 \mathrm{~nm})$. The separation conditions were as follows: column LiChrospher $100 \mathrm{RP}-18 \mathrm{e}, 250 \times 10 \mathrm{~mm}$, $\mathrm{dp}=10 \mu \mathrm{m}$. Mobile phase composition: $\mathrm{MeOH} / \mathrm{H}_{2} \mathrm{O}(68: 32)$, at a flow rate of $6.25 \mathrm{ml} \mathrm{min}{ }^{-1}$. The sample $(8.25 \mathrm{mg})$ dissolved in $\mathrm{MeOH} / \mathrm{H}_{2} \mathrm{O}(95: 5,625 \mu \mathrm{l})$ was injected. The retention time of the $3^{\prime}-N$-acetylcandicidin D methyl ester (2) was $43 \mathrm{~min}$. HPLC separation (12 times) gives $11 \mathrm{mg}$ of $\mathbf{2}$. The ESI-Q-TOF MS gave the signal of $m / z 1163.5973(\mathrm{M}-\mathrm{H})^{-}$; UV $\lambda_{\max }(\mathrm{MeOH}) 990(380) \mathrm{nm}$.

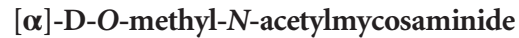

The $3^{\prime}-\mathrm{N}$-acetylcandicidin complex $(50 \mathrm{mg})$ was dissolved in a $10 \mathrm{ml}$ solution of $2 \% \mathrm{HCl}$ in methanol and stirred overnight. Then, the reaction mixture was neutralized with sodium carbonate, filtered and evaporated to dryness under reduced pressure. The product was isolated by flash chromatography on Merck Kieselgel 60, 0.063-0.200 mm, using the solvent system $\mathrm{CHCl}_{3} / \mathrm{MeOH}$ (5:1) to yield $[\alpha]$-D-O-methyl- $N$-acetylmycosaminide $(6 \mathrm{mg}),[\alpha]_{\mathrm{D}}^{20}+46.0$ $(\mathrm{c}=1, \mathrm{MeOH})$.

\section{MS spectra}

MS spectra were recorded with a 6540 UHD Accurate-Mass Q-TOF spectrometer using the negative ESI mode.

\section{IR spectra}

IR spectra of 3'-N-acetylcandicidin D methyl ester were measured using FT-IR with the ATR sampling mode (Nicolet 8700 FT-IR, Thermo Nicolet, Madison, WI, USA; Thermo Electron Corporation). Spectra were acquired at $2 \mathrm{~cm}^{-1}$ resolution in the spectral range $4500-500 \mathrm{~cm}^{-1}$ with 128 scans.

\section{UV-VIS spectrum}

The UV-VIS spectrum of $3^{\prime}-N$-acetylcandicidin D methyl ester was recorded with a PerkinElmer Lambda Bio UV/VIS spectrometer.

\section{Optical rotation}

The optical rotation of $3^{\prime}-N$-acetylcandicidin D methyl ester was measured with an Autopol II automatic polarimeter (Rudolph Research, Flanders, NJ, USA) in the solvent system pyridine- $d_{5}-$ methanol- $d_{4}, 9: 1(\mathrm{v} / \mathrm{v})$ with a sample concentration of $7.8 \mathrm{mg} \mathrm{ml}^{-1}$ at $\lambda=589 \mathrm{~nm}$. The recorded optical rotation value was $[\alpha]_{\mathrm{D}}^{20}+0.87$.

\section{NMR spectra}

The NMR spectra were recorded with a Varian Unity 500 Plus spectrometer in solvent system pyridine- $d_{5}-$ methanol- $d_{4}, 9: 1(\mathrm{v} / \mathrm{v})$ with a sample concentration of $10 \mathrm{mg} \mathrm{ml}^{-1}$.

The ${ }^{13} \mathrm{C}$ and one-dimensional ${ }^{1} \mathrm{H}$ spectra were collected using standard parameters.

Two-dimensional ${ }^{1} \mathrm{H}$ spectra were measured in the phase-sensitive mode with a spectral width of $4344 \mathrm{~Hz}$.

The DQF-COSY spectrum was acquired in a $6080 \times 750$ matrix with eight accumulations per increment and was processed in a $4 \mathrm{~K} \times 2 \mathrm{~K}$ matrix.

The NOESY spectrum was acquired with a mix time of $350 \mathrm{~ms}$ in a $2048 \times 320$ matrix with 16 accumulations per increment in a $2 \mathrm{~K} \times 1 \mathrm{~K}$ matrix.

The ROESY spectrum was acquired with a mix time of $300 \mathrm{~ms}$ in a $2048 \times 320$ matrix with 16 accumulations per increment in a $2 \mathrm{~K} \times 1 \mathrm{~K}$ matrix.

HSQC and HMBC experiments were performed with pulse field gradients.

The HSQC spectrum was acquired in the phase-sensitive mode. The spectral windows for ${ }^{1} \mathrm{H}$ and ${ }^{13} \mathrm{C}$ axes were $4344 \mathrm{~Hz}$ and $20111 \mathrm{~Hz}$, respectively. The data were collected in a $1728 \times 210$ matrix and processed in a $2 \mathrm{~K} \times 1 \mathrm{~K}$ matrix.

The HMBC spectrum was acquired in absolute value mode. The spectral windows for ${ }^{1} \mathrm{H}$ and ${ }^{13} \mathrm{C}$ axes were 4344 and $27024 \mathrm{~Hz}$, respectively. The data were collected in a $1920 \times 280$ matrix and processed in a $2 \mathrm{~K} \times 1 \mathrm{~K}$ matrix.

\section{ACKNOWLEDGEMENTS}

These studies were supported by the General Fund of the Chemical Faculty, Gdańsk University of Technology. The experimental IR data were obtained through the courtesy of Dr M. Śmiechowski.

1 Borowski, E. \& Schaffner, C. P. Structural relationships among the heptaene macrolide antibiotics. Abstract of Papers of Vth Internat. Congr. Of Biochem., Moscow p. 3 (Pergamon Press: London, 1961).

2 Lechevalier, H., Acker, R. F., Corke, C. T., Haenseler, C. M. \& Waksman, S. A. Candicidin, a new antifungal antibiotic. Mycol. 45, 155-171 (1953).

3 Waksman, S. A., Lechevalier, H. A. \& Schaffner, C. P. Candicidin and other polyenic antifungal antibiotics. Bull. Wld HIth Org. 33, 219-226 (1965).

4 Ślisz, M. et al. The mechanism of overcoming multidrug resistance (MDR) of fungi by amphotericin B and its derivatives. J. Antibiot. 60, 436-446 (2007).

5 Gordon, H. W. \& Schaffner, C. P. The effect of polyene macrolides on the prostate gland and canine prostatic hyperplasia. Proc. Natl Acad. Sci. USA 60, 1201-1208 (1968).

6 Malewicz, B., Momsen, M., Jenkin, H. M. \& Borowski, E. Potentiation of antiviral activity of acyclovir by polyene macrolide antibiotics. Antimicrob. Ag. Chemother. 25, 772-774 (1984).

7 Schaffner, C. P. \& Borowski, E. Polyenic compounds and procedures related thereto. US3244590 (1966).

8 Pawlak, J., Sowiński, P., Bieszczad, T. \& Borowski, E. The structure of levorin $A_{3}$, a minor component of levorin complex. Polish J. Chem. 79, 1667-1672 (2005).

9 Szwarc, K., Szczeblewski, P., Pawlak, J., Sowiński, P. \& Borowski, E. The structure of levorin $A_{1}$, a minor component of levorin complex. Book of Abstracts of 7th NMR in chemistry, physics and biological sciences P-35 (Warsaw: Poland, 2012).

10 Komori, T., Morimoto, Y., Niwa, M. \& Hirata, Y. Structure of trichomycin A, a polyene macrolide from Streptomyces. Tetrahedron Lett. 30, 3813-3816 (1989).

11 Komori, T. Trichomycin B, a polyene macrolide from Streptomyces. J. Antibiot. 43, 778-782 (1990).

12 Wright, J. J., Greeves, D., Mallams, A. K. \& Picker, D. H. Structural elucidation of heptaene macrolide antibiotics 67-121-A and 67-121-C. J. Chem. Soc. Chem. Commun. 710-712 (1977).

13 Pawlak, J., Sowiński, P. \& Borowski, E. Stereostructure of perimycin A. J. Antibiot. 48, 1034-1038 (1995).

14 Sowiński, P., Gariboldi, P., Pawlak, J. K. \& Borowski, E. The structure of vacidin A, an aromatic heptaene macrolide antibiotic. II. Stereochemistry of the antibiotic. J. Antibiot. 42, 1639-1642 (1989).

15 Tweit, R. C., Pandey, R. C. \& Rinehart, K. L. Characterization of the antifungal and antiprotozoal antibiotic partricin and structural studies on partricins $A$ and $B$. J. Antibiot. 35, 997-1112 (1982).

16 Sowiński, P., Pawlak, J. K., Borowski, E. \& Gariboldi, P. Stereostructure of gedamycin. Polish J. Chem. 69, 213-217 (1995).

17 Zieliński, J. et al. The structure of levorin $A_{2}$ and candicidin D. Tetrahedron Lett. 20, 1791-1794 (1979).

18 Barlow, L. \& Pattenden, G. Synthesis of poly-Z-isomers of 2,6,11,15-Tetramethylhexadeca-2,6,8,10,14-pentaene, a C20 analogue of phytoene. Re-examination of the stereochemistry of a new isomer of phytoene from Rhodospiriflum rubrum. J. Chem. Soc., Perkin Trans. 1, 1029-1034 (1976). 
19 Pawlak, J., Sowiński, P. \& Borowski, E. Stereostructure and NMR characterization of the antibiotic candidin. J. Antibiot. 46, 1598-1604 (1993)

20 Płosiński, M., Laskowski, T., Sowiński, P. \& Pawlak, J. Stereostructure of mycoheptin A. Magn. Reson. Chem. 50, 818-822 (2012)

21 Barber, M. S., Hardisson, A., Jackman, L. M. \& Weedon, B. C. L. Studies in nuclear magnetic resonance. Part IV. Stereochemistry of the Bixins. J. Chem. Soc 1625-1630 (1961).
22 Dutcher, J. D., Walters, D. R. \& Wintersteiner, O. Nystatin. III. Mycosamine preparation and determination of structure. J. Org. Chem. 28, 995-999 (1963).

23 Saltza, M., Dutcher, J. D., Reid, J. \& Wintersteiner, O. Nystatin. IV. The stereochemistry of Mycosamine. J. Org. Chem. 28, 999-1004 (1963).

24 Saltza, M., Reid, J., Dutcher, J. D. \& Wintersteiner, O. Nystatin. II. The stereochemistry of Mycosamine. J. Am. Chem. Soc. 83, 2785-2785 (1961). 